\title{
Evaluation of Renal Function Parameters in Normotensive and Pre-Eclamptic Pregnant Women at Different Stages of Pregnancy
}

${ }^{1}$ Farhana Mukhtar, ${ }^{1}$ Tahira Naseem, ${ }^{1}$ Mahnoor Khan, ${ }^{2}$ Rafiq Siddiqui, ${ }^{1}$ Shazia Hameed, ${ }^{3}$ Faria Latif Sami, ${ }^{4}$ Anoud Naeem

${ }^{1}$ Department of Biochemistry\& Chemical Pathology, Shaikh Zayed Medical Complex, Lahore

${ }^{2}$ Department of Biochemistry, Services Institute of Medical Sciences, Lahore

${ }^{3}$ Department of Medicine, Jinnah Hospital, Lahore

\begin{abstract}
Introduction: Pre-eclampsia is one of the most common causes of maternal and fetal complications in developing countries. Owing to its multisystem involvement, hypertension and proteinuria in pre-eclamptic women may lead to acute or chronic renal failure. Early diagnosis is vital to avoid this organ failure. Aims \& Objectives: To assess renal function by measuring and comparing four renal function parameters including Blood urea Nitrogen (BUN),serum creatinine, creatinine clearance and 24-hr urinary protein in pre-eclamptic and normotensive pregnant women at different stages of pregnancy. Place and duration of study: This prospective and observational study was conducted in 2009 at Shaikh Zayed Hospital. The patients were taken from Gynae and Obstetrics OPD, with 24 weeks of gestation. Material \& Methods: In this study, 25 normotensive Controls and 25 pre-eclamptic pregnant women (cases) were included. Serum and urinary samples were taken at 24 weeks, 28 weeks, 32 weeks of gestation as well as at term (38 weeks). Blood urea nitrogen (BUN), serum creatinine, spot urinary protein and urinary creatinine were measured by clinical Chemistry Auto analyzer Dimension AR. Whereas, 24 hours urinary protein and creatinine clearance were calculated later. Results: BUN level of cases were significantly high as compared to controls at 32 weeks and at term $(\mathrm{p}<0.01)$ however creatinine clearance was found to be significantly low $(\mathrm{p}>0.05)$ in pre-elamptic women only at 38 weeks. Apart from other results, 24-hours urinary protein was found to be significantly high $(\mathrm{p}<0.05)$ in pre-eclamptic women as compared to normotensive women at all stages of pregnancy. Conclusion: Our study showed that BUN, Creatinine clearance and most importantly 24-hr urinary protein may be used to assess the renal function in relation with the severity of pre-eclampsia.
\end{abstract}

Key words: Pre-eclampsia, Blood Urea Nitrogen (BUN), Proteinuria.

\section{INTRODUCTION}

$\mathrm{P}$ re-eclampsia is a potentially life-threatening complication of pregnancy. It has been described as hypertension (systolic blood pressure $\geq 140 \mathrm{mmHg}$ and/or diastolic blood pressure $\geq 90 \mathrm{mmHg}$ ) associated with proteinuria (24-hours protein excretion $\geq 300 \mathrm{mg}$ ) diagnosed after 20 weeks of uneventful gestation upto 2 week postpartum. ${ }^{1}$ Delivery serves to cure the mother from high blood pressure and proteinuria also vanishes within a few weeks postpartum. ${ }^{2}$ Pre-eclampsia has deleterious effects on maternal and fetal health especially in the developing areas of the world. ${ }^{3}$ Physiologically, in healthy pregnant women, a rapid rise in renal blood flow and increase in GFR (glomerular filtration rate) has been documented. ${ }^{4}$ Whereas, during preeclampsia, various impaired molecular pathways cause endothelial dysfunction that leads to a decrease in renal blood flow and glomerular filtration rate along with the appearance of proteinuria. Therefore, in pre-eclamptic women, the extent of proteinuria is considered to be a marker of endothelial dysfunction and severity of this disease. ${ }^{5}$ The hemodynamic and endothelial changes in preeclampsia make the kidneys more vulnerable to develop acute renal failure and rarely an irreversible form of this disease called renal cortical necrosis. ${ }^{4}$ Similarly, It has been documented that preeclamptic women are at a higher risk of end stage kidney disease and hypertension later in life. ${ }^{6}$

In this prospective study, all the major renal function markers including blood urea nitrogen, 
serum creatinine, creatinine clearance and 24 hours urinary protein were measured at four different gestational intervals namely 24 weeks, 28 weeks, 32 weeks and at term. The purpose of his study was to compare these renal function markers in normotensive and pre-eclamptic pregnant women in order to highlight their diagnostic role in the evaluation of kidney function during pre-eclampsia.

\section{MATERIAL AND METHODS}

This study was conducted in the Department of Biochemistry and Chemical Pathology, Shaikh Zayed Hospital, Lahore. Relevant patient data was collected between January to December 2009.

A total of fifty (50) subjects were taken, in which 25 Normotensive pregnant women were taken as controls and 25 pre-eclamptic pregnant women were taken as cases.

Blood and urine samples were taken at 24 weeks, 28 weeks, 32 week of gestation and at term. Blood urea nitrogen, serum creatinine, spot urinary protein and urinary creatinine were measured by clinical chemistry Autoanalyzer Dimension AR. Whereas 24 hours urinary protein and creatinine clearance were calculated at mentioned weeks of gestation for comparison along with controls and cases.

Inclusion criteria: Twenty five normotensive pregnant women of gestational age between 20 - 24 weeks and 25 pre-eclamptic pregnant women between 20 - 24 weeks of gestation were included in this study.

Exclusion Criteria: Women having hypertension due to any other cause like renal, hepatic or cardiac diseases were excluded from this study.

\section{Statistical analysis:}

SPSS 20.0 was used for data entry and analysis Pvalue was generated by one way ANOVA and t-test. A p-value less than 0.05 was considered significant. ${ }^{7}$

\section{RESULTS}

Normotensive controls and pre-eclamptic cases were investigated for BUN, Serum Creatinine, Creatinine Clearance and Urinary Protein at 24, 28, 32 and 38 weeks. There was no significant difference in results of BUN till 28 weeks but mean results of BUN of cases was significantly high $(p<0.01)$ as compare to controls at 32 weeks and at 38 weeks (Table- 1 ).

There was no significant change in results of serum creatinine $(p>0.05)$ in controls and pre-eclamptic cases throughout all gestational weeks. On contrary to it, results of 24 hours urinary protein were significantly high $(\mathrm{p}<0.05)$ in pre-eclamptic cases as compared to normotensive controls at all intervals of gestation (Table-1). Additionally, although creatinine clearance of controls and cases was not found significantly low till 28 weeks but at $32 \& 38$ weeks it was found to be significantly low $(p<0.05)$ in the pre-eclamptic cases (Table-1).

\begin{tabular}{|c|c|c|c|c|c|}
\hline & Weeks & $\begin{array}{l}\text { BUN } \\
\mathrm{mg} / \mathrm{dl}\end{array}$ & $\begin{array}{c}\text { Creatinine } \\
\mathrm{mg} / \mathrm{dl}\end{array}$ & $\begin{array}{c}\text { Creatinine } \\
\text { clearance } \\
\mathrm{ml} / \mathrm{min}\end{array}$ & $\begin{array}{c}\text { Urinary } \\
\text { Protein } \\
\text { mg/dl }\end{array}$ \\
\hline \multirow{4}{*}{ 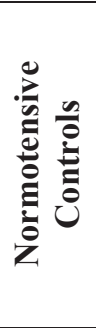 } & 24 & $\begin{array}{c}9.76 \pm \\
0.24\end{array}$ & $\begin{array}{c}0.74 \pm \\
0.23\end{array}$ & $\begin{array}{c}105.0 \pm \\
1.60\end{array}$ & $\begin{array}{c}143.88 \pm \\
7.82\end{array}$ \\
\hline & 28 & $\begin{array}{c}8.24 \pm \\
0.16 \\
\end{array}$ & $\begin{array}{c}0.81 \pm \\
0.24\end{array}$ & $\begin{array}{c}99.46 \pm \\
1.27 \\
\end{array}$ & $\begin{array}{c}158.96 \pm \\
7.16 \\
\end{array}$ \\
\hline & 32 & $\begin{array}{c}8.88 \pm \\
0.20 \\
\end{array}$ & $\begin{array}{c}0.86 \pm \\
0.20\end{array}$ & $\begin{array}{c}94.01 \pm \\
0.91\end{array}$ & $\begin{array}{c}160.58 \pm \\
7.41 \\
\end{array}$ \\
\hline & At term & $\begin{array}{c}10.60 \pm \\
0.21\end{array}$ & $\begin{array}{c}0.91 \pm \\
0.23\end{array}$ & $\begin{array}{c}88.68 \pm \\
1.47\end{array}$ & $\begin{array}{c}181.80 \pm \\
6.77 \\
\end{array}$ \\
\hline \multirow{4}{*}{ 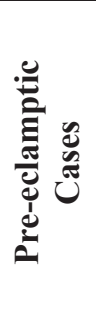 } & 24 & $\begin{array}{c}10.02 \pm \\
3.5\end{array}$ & $\begin{array}{c}0.76 \pm \\
0.21\end{array}$ & $\begin{array}{l}100.86 \pm \\
2.04\end{array}$ & $\begin{array}{l}174.48 \pm \\
11.45 * *\end{array}$ \\
\hline & 28 & $\begin{array}{c}10.72 \pm \\
0.34\end{array}$ & $\begin{array}{c}0.86 \pm \\
0.20 \\
\end{array}$ & $\begin{array}{c}94.89 \pm \\
1.78 \\
\end{array}$ & $\begin{array}{c}184.76 \pm \\
9.38 * *\end{array}$ \\
\hline & 32 & $\begin{array}{l}11.92 \pm \\
0.39 * *\end{array}$ & $\begin{array}{c}0.87 \pm \\
0.18\end{array}$ & $\begin{array}{l}91.35 \pm \\
1.27 * *\end{array}$ & $\begin{array}{l}205.68 \pm \\
10.32 * *\end{array}$ \\
\hline & At term & $\begin{array}{c}13.6 \pm \\
0.44^{* *}\end{array}$ & $\begin{array}{c}0.98 \pm \\
0.16\end{array}$ & $\begin{array}{l}80.38 \pm \\
0.65 * *\end{array}$ & $\begin{array}{c}220 \pm \\
10.46^{* *}\end{array}$ \\
\hline
\end{tabular}

Table-1: Comparison of Renal Parameters in Normotensive Controls and Pre-eclamptic cases.

\section{DISCUSSION}

Pre-eclampsia remains to be a disease of concern due to its numerous adverse outcomes. Out of these, acute and chronic renal disorders are serious complications as they may lead to subsequent renal failure. ${ }^{7}$ It has been reported that risk of ESRD (End Stage Renal Disease) increases with recurrent episodes of pre-eclampsia in two or more pregnancies. ${ }^{8}$

Keeping in view the reported facts this study aims to compare four renal function biomarkers at different intervals of pregnancy $(24,28,32$ weeks and term) both in normotensive controls and pre-eclamptic cases. This may help in the evaluation of their diagnostic role in this disease. Timely diagnosis and management is vital to avoid maternal and fetal morbidity and mortality associated with it.

In our study, when compared the results depicted a significant difference in the BUN values of cases and controls at 32 weeks of gestation as well as at term. These observations were similar to the ones of the study conducted in Nigeria in 2018. ${ }^{9}$ On the other hand, serum creatinine manifested no 
significant difference in both groups throughout pregnancy. In accordance with our findings, some prior studies also observed statistically insignificant change in serum creatinine of the two cited groups. ${ }^{10,11}$ Moreover, another research, reported increased serum creatinine levels in the preeclamptic cases but stated it to be of no predictive value in pre-eclampsia. ${ }^{12}$

Lastly and most importantly, the pre-eclamptic cases were observed to have significantly high levels of 24 hours urinary protein as compared to normotensive controls at all intervals of gestation. This significant rise in the proteinuria of these patients was in accordance with the findings of various other studies as well. ${ }^{2,9,13} \mathrm{~A}$ meta-analysis by Mc Donald et al has confirmed the association between pre-eclampsia and persistent proteinuria. ${ }^{14}$ It is also stated that progressive proteinuria is actually the consequence of endothelial dysfunction in pre-eclampsia and serves as an indicator of impaired renal function beyond pregnancy. ${ }^{2}$ In conformity, some other studies have also emphasized the increased risk of renal disease after pre-eclampsia. ${ }^{15,16}$

Among all the renal function parameters assessed in this study, BUN and creatinine clearance in last stages of pregnancy were indicative of renal damage in pre-eclamptic cases. Whereas, raised 24 hours proteinuria in pre-eclamptic cases, emerges out to be the most significant diagnostic and prognostic indicator of renal dysfunction throughout gestation. ${ }^{17,18}$

Owing to the long-term deleterious consequences of pre-eclampsia, early diagnosis remains the most important factor leading to timely management and prevention of its complications. A larger scale prospective study of these parameters may serve to further demonstrate the diagnostic significance of these renal biomarkers.

\section{CONCLUSION}

Amongst all the renal function markers, 24 hours urinary protein is suggested to be the most promising early diagnostic and prognostic marker of pre-eclampsia at all stages of gestation. We can assess renal damage in preeclamptic patients by measuring creatinine clearance in later stages, The patient should be managed early and timely to prevent renal complications.

\section{REFERENCES}

1. American College of Obstetricians and Gynecologists; Task force on Hypertension in pregnancy: Hypertension in pregnancy. Report of the American College of obstetricians and Gynecologists' Task force on Hypertension in pregnancy. Obstet Gynecol 122: 1122-1131, 2013.

2. T. Kaleta, A. Stock, D. panayotopoulas, O. Vonend, D. Niederacho, M. Neumann et al. Predictors of impaired post partum renal function in women after pre-eclampsia: Results of a prospective single center study. Disease Markers 2016. htpp://dx.doi.org/10.1155/2016/7861919

3. R. Pijnenborg, L. vercruysse and M. Hanssens. The uterine spiral arteries in human pregnancy: facts and controversies". Placenta 2006. Vol 27(9-10);939-958.

4. R. Mustafa, S. Ahmed, A Gupta, R. C. Veruto. A comprehensive review of Hypertension in pregnancy. Journal of Pregnancy 2012. http://dx.doi.org/10.1155/2012/105918

5. R. Lafayette. "The kidney in pre-eclampsia". Kidney International 2005; 67(3): 1194-1203.

6. A. G. Kattah, D. C. Scantelbury, S. Agarwal et al. Preeclampsia and ESRD. The role of shared risk factors". American Journal of Kidney Diseases 2017; vol 69(4): 498-505.

7. Fathalla MA, Fathalla MMF: A practical guide for health researches, World Health Organization. 2004; 87-105

8. B. E. Vikse, L. M. Irgens, T. Leivestad, R. Skjaerven and B. M. Iversen. "Pre-eclampsia and the risk of end-stage renal disease". The new England Journal of Medicine 2008; Volume 359 (8): page 800-9.

9. E. Oloruntoba, O. M. Olumatumininu, M. C. Cheistian and O. O. Nkeiruka. "Biochemical Assessment of renal and liver function amoung pre-eclamptics in Logos Metropolis". International Journal of Reproductive Medicine 2018. https://doi.org/10.1155/1155/2018/1594182

10. Salako BL, Odukogloe AT, Olayemi O, Adedapo KS, Aimakho CO, Alu FE et al. Serum albumin, creatinine, uric acid and hypertensive disorders of pregnancy. East African Med J. 2003; 80: 424-8.

11. B. L. Salako, O. Olayemi, A.T.A. Odukogloe et al. "Microalbuminuria in pregnancy as a predictor of pre-eclampsia." West African Journal of Medicine 2003; 22(4): page 295-300.

12. T. Ilanchezhian, R. Shanmuga Priya, S. Suganya, Balaji Rajagopalan. A Study to evaluate the renal function parameters in preeclampsia. International journal of pharmaceutical sciences and research. 2017; 8(1): 213-6. 
13. J. Miller-Deile, M. Schiffer, 'Pre-eclampsia from a renal point of view: Inside into disease models, biomarkers and therapy. "World Journal of Nephrology 2014; 3(4): 169-181.

14. S. D. McDonald, Z. Han, M. N. Walsh, C. Gerstain, P. J. Devereause. 'Kidney Diseases after pre-eclampsia: A systemic review and meta-analysis". American Journal of Kidney Diseases 2010; 55(6): page 1026-39.

15. I. K. Wang, C. H. Muo, Y. C, Chang et al. Association between hypertensive disorders during pregnancy and end-stage renal disease: a population-based study. Canadian Medical Association Journal 2013; 185(3); page 207-213

16. B. E. Vikse, L. M. Irgens, T. Leicestad, R. Skjaerven, B. M. Iversen. "Pre-eclampsia and the risk of end-stage renal disease." The Nen England Journal of Medicine 2008; 359(8): page 800-9.

17. E. B. Magnussen, L. J. Vatten, G. D. Smith and P. R. Romundstad. Hypertensive disorders in pregnancy and subsequently measured cardiovascular risk factors. Obstetrics and Gynecology 2009; 114(5); page 961-70.

18. J. W. Rich-Eduards, T. F. McElrath, S. A. Karumanclin and E. W. Seely. "Breathing life into the life course approach: pregnancy history and cardiovascular disease in women". Hypertension 2010; 56(3): page 1126-34.

\section{The Authors:}

Dr. Farhana Mukhtar

Associate Professor,

Department of Chemical Pathology,

Shaikh Zayed Medical Complex, Lahore.

Prof. Tahira Naseem

HOD Biochemistry \& Chemical Pathology, Shaikh Zayed Medical Complex, Lahore.

Dr. Mahnoor Khan

Assistant Professor,

Department of Biochemistry,

Shaikh Zayed Medical Complex, Lahore.

Dr. Faria Latif Sami

House Officer,

Department of Medicine,

Jinnah Hospital, Lahore.

Dr. Shazia Hameed

Assistant Professor,

Department of Chemical Pathology,

Shaikh Zayed Medical Complex, Lahore.

\section{Corresponding Author:}

Dr. Farhana Mukhtar

Associate Professor,

Department of Chemical Pathology,

Shaikh Zayed Medical Complex, Lahore.

E-mail: drfarhana90@gmail.com 